\title{
Interfacing Functional Systems
}

\author{
Yoann Cotelle ${ }^{a}$, Nicolas Chuarda, Santiago Lascano ${ }^{a}$, Vincent Lebrun ${ }^{b}$, Robin Wehlauch ${ }^{c}$, \\ Nadine Bohnic, Samuel Lörcher ${ }^{b}$, Viktoriia Postupalenko ${ }^{b}$, Sai T. Reddy ${ }^{d}$, Wolfgang Meier ${ }^{b}$, \\ Cornelia G. Palivan ${ }^{\mathrm{b}}$, Karl Gademann ${ }^{\mathrm{c}}$, Thomas R. Ward ${ }^{\mathrm{b}}$, and Stefan Matile ${ }^{\star_{\mathrm{a}}}$
}

\begin{abstract}
The objective of molecular systems engineering is to move beyond functional components and primary systems, towards cumulate emergent properties in interfaced higher-order systems of unprecedented multifunctionality and sophistication.
\end{abstract}

Keywords: Anion- $\pi$ interactions - Catalysis · Cellular uptake · Complexity - Dynamic covalent bonds Emergent properties - Molecular systems engineering - Multicomponent surface architectures . Multifunctionality $\cdot$ Photosystems $\cdot$ Polymersomes $\cdot$ Proteins $\cdot$ Systems chemistry

Reflecting novelty and complexity of the field, molecular systems engineering (MSE) can be defined in different ways, from different points of view. ${ }^{[1]}$ For an arguably simplifying definition based on interfacing and emergent properties, functional units of free choice are taken as primary components (Fig. 1). Independent of size and nature, primary components can be small molecules (catalysts, ${ }^{[2,3]}$ transporters, ${ }^{[3,4]}$ chromophores, ${ }^{[5]}$ vitamins, ${ }^{[6]}$ bioadhesives ${ }^{[7]}$ ), macromolecules (enzymes, proteins, ${ }^{[6,8]}$ polymers $\left.{ }^{[5,9]}\right)$, supramolecules (protein oligomers, ${ }^{[6,8]}$ polymersomes, ${ }^{[9]}$ liposomes $\left.{ }^{[3]}\right)$, cells, ${ }^{[4,8]}$ devices, ${ }^{[5,7]}$ and so on. Interfacing of primary components non-covalent, dynamic-covalent or covalent - produces primary systems. Primary systems are characterized by properties that are absent in the individual primary components, i.e. emergent properties. Systems chemistry focuses on primary systems (one out of several possible definitions circulating in the community). Primary systems have also received significant attention in the context of supramolecular chemistry, although often more from a structural than from a functional point of view. The general objective of molecular systems engineering is to move beyond the primary systems and focus on the interfacing of systems with systems (or components) to afford coupled systems (or 'interfaced systems', 'systems of systems', 'complex systems', 'higher-order systems', etc.), characterized by new emergent properties. The simplest coupled system, a formally secondary system, is thus by definition trifunctional with respect to the engineering operations applied. Continuing interfacing affords tertiary systems, quaternary systems, etc., with emergent properties and thus increasing multifunctionality and/or sophistication.

One of the simplest primary components of current interest in the NCCR MSE is nothing more than an aromatic surface (Figs 2 and 3). The function of interest of this primary component is the binding of holes (oxidation), cations, cationic reactive intermediates or cationic transition states on $\pi$-basic surfaces and the binding of electrons (reduction), anions, anionic reactive intermediates or anionic transi- tion states on $\pi$-acidic surfaces. ${ }^{[2]}$ Whereas cation- $\pi$ interactions in all different forms are very well documented, anion- $\pi$ and ionpair- $\pi$ interactions are of current interest because they are almost unexplored in functional systems. ${ }^{[2,10]}$ For several good reasons, naphthalenediimides (NDIs) such as $\mathbf{1}$ offer the $\pi$-acidic surface of choice for a promising primary component (Fig. 2). Interfacing with a carboxylate base, a functional component, through a Leonard turn affords the formal covalent primary system 2 (Figs 2 and 3). The emergent property is catalysis of the Kemp elimination. ${ }^{[11]}$ Covalent interfacing of primary system 2 with a proline base, another functional component, through an extended turn affords a covalently coupled, formally secondary system 3. ${ }^{[2]}$ The emergent property is the catalysis of enamine addition to nitroolefins, a much more important reaction than the Kemp elimination catalyzed by the primary system. Interfacing with chiral sulfoxides at the edge of the $\pi$-acidic surface yields the formally tertiary covalent coupled system 4. ${ }^{[2]}$ The emergent property is stereoselectivity, i.e. asymmetric
${ }^{*}$ Correspondence: Prof. S. Matile

E-mail: Stefan.Matile @unige.ch

aDepartment of Organic Chemistry

University of Geneva, Geneva

${ }^{b}$ Department of Chemistry

University of Basel, Basel

'Department of Chemistry

University of Zurich, Zurich

dDepartment of Biosystems Science and Engineering (D-BSSE)

ETH Zurich, Basel

${ }^{a-d}$ National Centre of Competence in Research

(NCCR) Molecular Systems Engineering

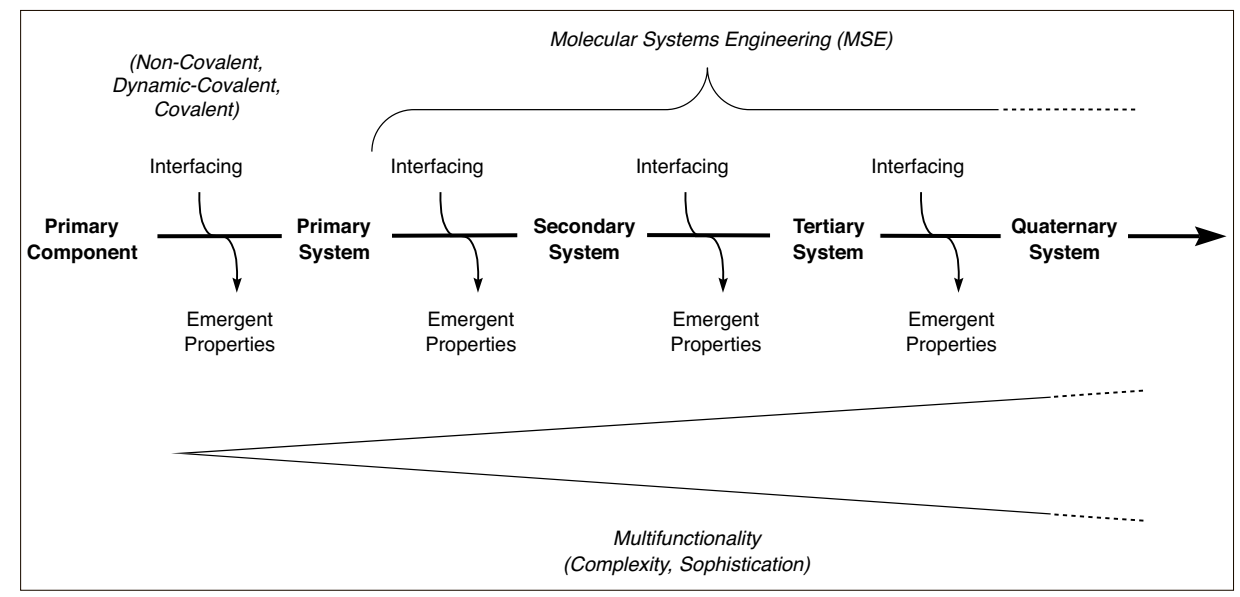

Fig. 1. A definition of molecular systems engineering based on interfacing, emergent properties and increasing multifunctionality and sophistication. 
catalysis with a formally tetrafunctional system composed of a) a $\pi$-acidic surface to stabilize anionic transition states and reactive intermediates, b) a proline base to activate the aldehyde substrate as enamine c) a glutamic acid to protonate the nitronate intermediate, and d) chiral sulfoxides to assure stereoselectivity.

One general objective within the NCCR MSE will be to continue interfacing of coupled systems such as $\mathbf{4}^{[2,12]}$ with the challenge to cumulate significant emergent properties beyond simple additivity. Limited only by our imagination, functional components or systems conceivable for interfacing reach from additional simple but meaningful functional groups to solid surfaces, ${ }^{[5,13-17]}$ proteins, ${ }^{[6]}$ polymersomes, ${ }^{[9]}$ liposomes, ${ }^{[3]}$ cells, ${ }^{[4]}$ and so on. Success with MSE will ultimately be judged from the significance, practical or conceptual, of the emergent properties obtained.

Dynamic covalent bonds are most attractive for systems interfacing because they can be reversible like non-covalent bonds and, under different conditions, exist as irreversibly as covalent bonds. ${ }^{[4,5,13-17]}$ For systems interfacing, this dual nature promises access to self-sorting, self-healing, adaptability, templation, amplification, replication, transcription, and so on. ${ }^{[18]}$ polymerization under basic conditions. [12] The emergent property of the $\pi$-stacked chromophores in primary system $\mathbf{5}$ is charge transport. Yellow NDIs with two ethoxy substituents in the core were used in original SOSIP architectures because their stacks are able to separate charges and transport both holes and electrons, the single channels in primary system $\mathbf{5}$ were sufficient to generate photocurrent, i.e. convert light into current.

Orthogonal to disulfide exchange, hydrazone exchange under acidic conditions is used to add $\pi$ stacks along the original stacks in primary system 5. ${ }^{[14]}$ The resulting secondary system $\mathbf{6}$ contains co-axial channels that transport holes and electrons separately. Charge separation into these coaxial channels can be named as unifying emergent property of double-channel photosystem 6 that affects several functional readouts. Interfacing with orthogonal dynamic covalent chemistry makes stack exchange very straightforward and thus adds access to structural and functional diversity as another general emergent property with secondary system $\mathbf{6}$.

The integration of antiparallel redox gradients into double-channel photosystems 6 can be considered as an interfacing process. In the example shown, domains of EDOT acceptors and thiazole donors are placed in the oligothiophene channel to drive holes away from the solid surface, whereas fullerenes with three, two and one cyclopropane are interfaced to drive electrons toward the solid surface. ${ }^{[5]}$ Transcribing one of the more complex lessons from nature toward the materials sciences, the emergent property of the resulting, formally tertiary coupled system $\mathbf{6}$ is the nearly complete elimination of charge recombination. ${ }^{[5]}$

Boronic ester exchange has been introduced recently for the interfacing of a third stack under neutral conditions with a third orthogonal dynamic covalent bond.[15] Compatible with structural diversity, emergent properties reported for the tertiary system 7 include sensing (polyphenols in green tea), ${ }^{[15,19]}$ spectral tuning (plant flower anthocyanines) or the stabilization of unstable structures (tritylium cations). ${ }^{[16]}$ From there, future perspectives for MSE are as described for covalent systems with the exception that special attention to dynamic-covalent interfacing strategies might become particularly rewarding: Boronic ester exchange is so far not fully orthogonal to hydrazone and disulfide exchange, ${ }^{[7,15]}$ and the fourth orthogonal organic dynamic covalent bond remains to be discovered.

For non-covalent MSE, streptavidin 8

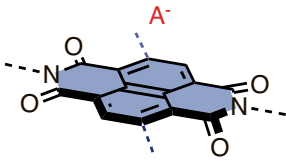

Primary Component

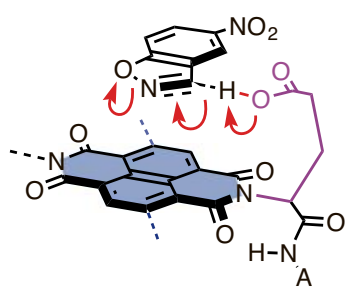

2

Primary System

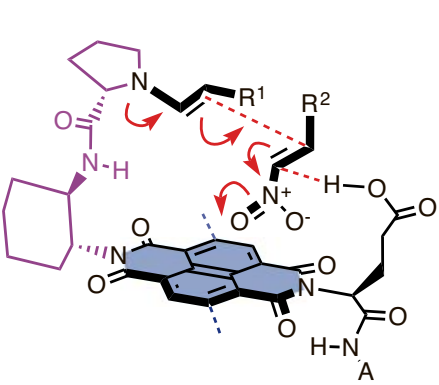

3

Secondary System

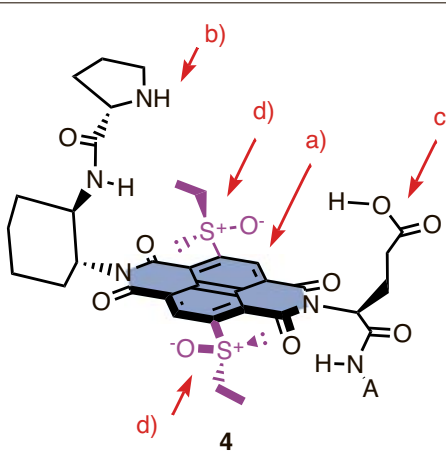

Tertiary System

Fig. 2. Covalent coupled systems: $A \pi$-acidic aromatic surface $\mathbf{1}$ as primary component (blue; primary function: anion binding) is interfaced with a carboxylate to give primary system 2 (emergent property: catalysis of Kemp elimination (red arrows), an amine for secondary system $\mathbf{3}$ (emergent property: catalysis of enamine addition) and sulfoxides for tertiary system $\mathbf{4}$ (emergent property: stereoselectivity) with four distinct, covalently interfaced components contributing to function (a-d). Compare Fig. 3 for explicit systems analysis.

These expected advantages of dynamiccovalent chemistry for systems engineering have been validated with multicomponent photosystems on solid surfaces (Figs 4 and 5). ${ }^{[5,13-17]}$ A chromophore is taken as a primary component with absorption and emission as intrinsic properties. The alignment of these primary components in oriented $\pi$ stacks on conducting solid oxide surfaces affords primary system 5 (Fig. 4). The interfacing is achieved with SOSIP, a recently introduced method that operates by ring-opening disulfide-exchange

\begin{tabular}{|c|c|c|c|c|}
\hline & System & Component & Emergent Property & Interfacing \\
\hline & - & $\pi$ Surface & - & - \\
\hline & Primary System & Carboxylate & Kemp Elimination & Leonard Turn \\
\hline & Secondary System & Amine & Enamine Addition & Extended Turn \\
\hline MSE & Tertiary System & Sulfoxides & Stereoselectivity & $\begin{array}{l}\text { Core Substitution, } \\
\text { Oxidation }\end{array}$ \\
\hline & $\downarrow$ & \rfloor & $\downarrow$ & \rfloor \\
\hline
\end{tabular}

Fig. 3. Covalent coupled systems analyzed in the context of molecular systems engineering. Compare Fig. 2 for structures and Fig. 1 for definitions. 


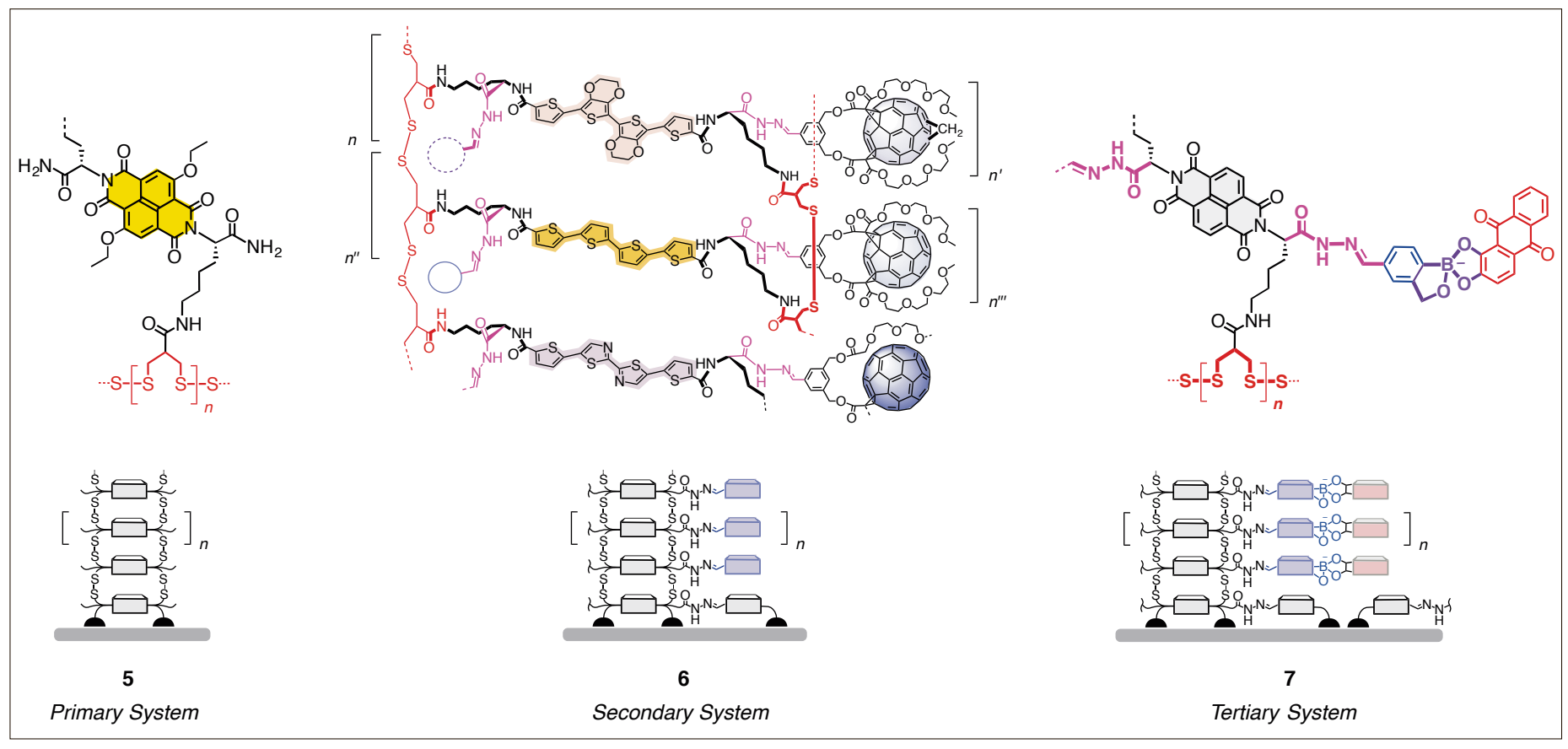

Fig. 4. Dynamic-covalent coupled systems: A chromophore as primary component (primary function: absorption, emission) is engineered into primary system 5 (interfacing: disulfide exchange (red), emergent property: charge transport), secondary system 6 (interfacing: hydrazone exchange (magenta), emergent property: charge separation) and tertiary system $\mathbf{7}$ (interfacing: boronic exchange (violet), emergent property: sensing). Compare Fig. 5 for explicit systems analysis.

is a privileged, exceptionally versatile principal component (Figs 6 and 7).[6] It is a tetrameric protein with four identical, extremely strong binding sites for biotin. Attached to biotin, organometallic catalysts for new-to-nature reactions have been successfully interfaced with the protein. Moreover, mutant libraries of streptavidin have been introduced as an exceptionally powerful tool to screen the resulting primary systems 9 for emergent properties such as asymmetric catalysis, i.e. stereoselectivity. ${ }^{[6,20,21]}$

Alternatively, streptavidin has been equipped with transporters such as cellpenetrating poly(disulfide)s (CPDs). ${ }^{[4,22]}$ The resulting primary systems $\mathbf{1 0}$ turned out to enter cells as easily as expected. Understood structural modifications of the CPDs have been applied to direct the streptavidin to specific intracellular targets such as the nucleoli. The emergent property of non-covalent primary system $\mathbf{1 0}$ composed of streptavidin and CPDs can thus be considered as directional access to intracellular compartments, or simply uptake.

The interfacing of streptavidin with two different biotin conjugates provides access to non-covalent secondary systems. ${ }^{[4]}$ This possibility has been exemplified with complex 11 composed of streptavidin, biotinylated CPDs plus a biotinylated redemitting fluorophore as a model substrate. The result were red-fluorescent nucleoli. These findings identified biotin-streptavidin-based secondary systems like $\mathbf{1 1}$ as excellent engineering tools to interface cells with any object of interest within the NCCR MSE. Promising topics reach from

\begin{tabular}{|c|c|c|c|}
\hline System & Component & Emergent Property & Interfacing \\
\hline - & Chromophore & - & - \\
\hline Primary System & п Stack (Single Channel) & Charge Transport & Disulfide Exchange \\
\hline Secondary System & Double Channel & Charge Separation & Hydrazone Exchange \\
\hline Tertiary System & $\begin{array}{l}\text { a) Antiparallel Gradient } \\
\text { b) Triple Channel }\end{array}$ & $\begin{array}{l}\text { a) Charge Recombination } \\
\text { b) Sensing }\end{array}$ & $\begin{array}{l}\text { a) Sequential Exchange } \\
\text { b) Boronic Ester Exchange }\end{array}$ \\
\hline
\end{tabular}

Fig. 5. Dynamic-covalent coupled systems analyzed in the context of molecular systems engineering. Compare Fig. 4 for structures and Fig. 1 for definitions.

innovative catalysts that run new-to-nature chemistry within cells to engineered nucleases that control gene expression.

Other marvelous primary components for non-covalent MSE are amphiphilic block copolymers. Composed of covalently linked hydrophobic and hydrophilic polymer domains, they self-assemble in aqueous environments into a variety of architectures, such as micelles, nanotubes or vesicles. In particular, amphiphilic diand tri-block copolymers poly(2-methyl2-oxazoline)- $b$-poly(dimethylsiloxane)$b$-poly(2-methyl-2-oxazoline) (PMOXA$b$-PDMS- $b$-PMOXA, 12) with appropriate hydrophobic-to-hydrophilic ratio self-assemble into primary systems called polymersomes $\mathbf{1 3}$ (Figs 8 and 9). Complementary to liposomes formed by biological lipids, polymersomes represent an important platform for development of reaction spaces at the nanoscale in MSE. During the membrane assembly, the in- dividual characters of the homopolymers domain yield a fluidic (PDMS) but robust (PMOXA) membrane. ${ }^{[23]}$ Despite the hydrophobic mismatch, the polymer membrane of these compartments represents an excellent platform for membrane proteins, synthetic pores or bio-pores interfacing. Polymersomes or liposomes equipped with membrane proteins, synthetic pores or photosystems are secondary systems (14). ${ }^{[3,24-27]}$ For example, the insertion of the ion selective bio-pore gramicidin into PMOXA- $b$-PDMS- $b$-PMOXA polymersomes allowed $\mathrm{H}^{+}, \mathrm{Na}^{+}$or $\mathrm{K}^{+}$ions to pass through the membrane and quench the fluorescence of encapsulated pyranine. The ion-dependent variation of the fluorescence intensity emerges from interfacing polymersomes with fluorophores, and biopores. ${ }^{[25]}$

The combination of pores with molecular recognition results in blockage, ligand gating and, ultimately, conceptually 


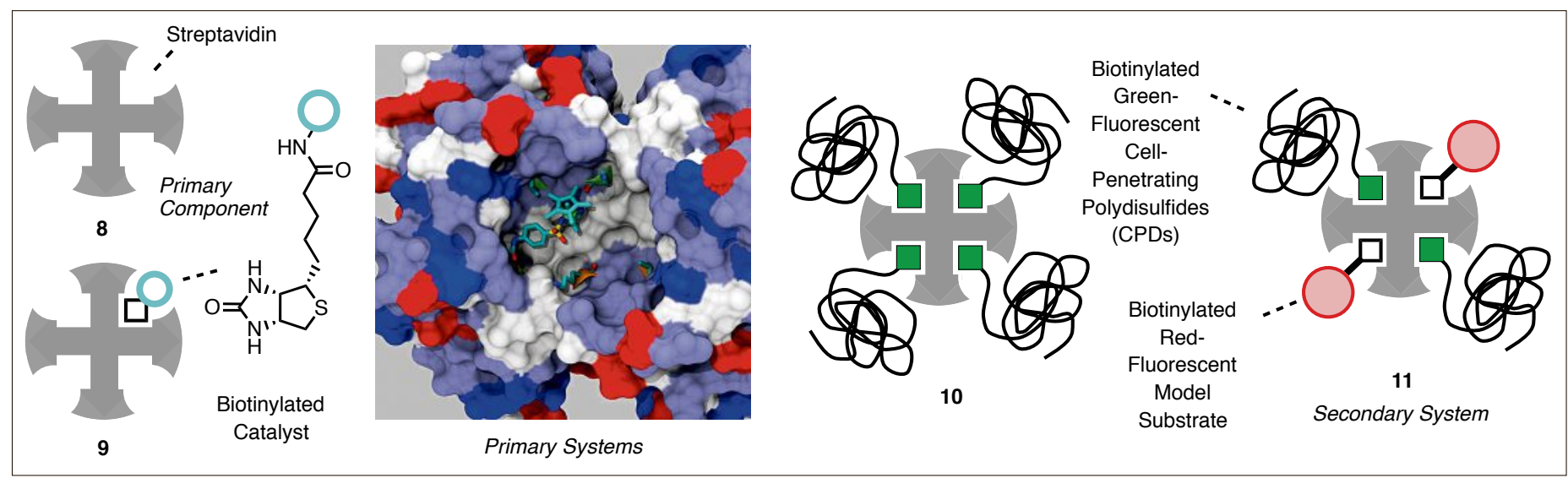

Fig. 6. Non-covalent coupled systems: Interfacing of streptavidin as non-covalent primary component 8 (primary function: binding) with transitionmetal catalysts yields artificial metalloenzymes as primary system $\mathbf{9}$ that catalyze new-to-nature reactions. Interfacing with CPDs affords primary system 10 that can enter into cells. Interfacing with CPDs and a fluorescent model substrate affords the secondary system $\mathbf{1 1}$ as cell-penetrating fluorescent probe. Compare Fig. 7 for explicit systems analysis. Insert: X-ray structure of an artificial imine reductase based on the biotin-streptavidin technology (PDB code: 3PK2). ${ }^{[21]}$

innovative stimuli-responsive membranes or sensors. ${ }^{[3,19,23,25-28]}$ The interfacing of pores in polymersomes and liposomes with enzymes and synthetic catalysts leads to tertiary systems $\mathbf{1 5}-\mathbf{1 7} \cdot .^{[3,29,30]}$ Such tertiary systems may interface with themselves to yield quaternary systems $\mathbf{1 8}$ or with cells in an analogue manner to yield simple artificial organelles. ${ }^{[29]}$ In a next round of interfacing, the pores or membrane proteins in a nanoreactor can be genetically/chemically modified to trigger in situ reactions or possibly release the cargo 'on demand'. OmpF, a bacterial porin, was chemically modified to accept a hydrazine to yield a hydrazone bound fluorophore, which blocked the pore. Interfacing this modified porin with polymersomes containing encapsulated horse radish peroxidase yielded pH-triggered nanoreactors. ${ }^{[30]}$

Assemblies from polymer blends of the attachment of a vast variety of molecules for targeting, catalytic network formation, as well as surface anchoring. For example, nanoreactors containing penicillin acylase were immobilized on amine-functionalized silicon surfaces to yield surfaces with emergent antimicrobial properties..[1] In another approach, polymersomes were functionalized with specific molecules such as anti-biotin IgG differently functionalized chains promote

or trastuzumab yielding primary systems capable of interfacing with cell surfaces or patterning of surfaces. ${ }^{[32]}$

The encapsulation of multiple enzymes working in polymersomes equipped with OmpF allowed the creation of the first artificial peroxisomes 17. Up-taken by cells, the artificial peroxisomes successfully detoxified in situ superoxide radicals and related $\mathrm{H}_{2} \mathrm{O}_{2} \cdot{ }^{[33]}$ A more complex scenario can be envisioned when different nanoreactors are interfaced to support complex cascade reactions, able to serve as core of molecular factories $\mathbf{1 8}$.

As an alternative to block copolymers, copolymers allow for molecular interfacing with emergent spatial organization of the interfacing sites due to functional group patterning along the polymer chains. The primary component $\operatorname{poly}(N-$ isopropylacrylamide-co-tris-nitrilotriacetic acid acrylamide) 19 was complexed with metal ions to facilitate site-specific reversible molecular recognition (Fig. 10). Interfacing $\mathrm{His}_{6}$-GFP with $\mathrm{Zn}^{2+}-19$ modulated the number of proteins per polymer chain 20. ${ }^{[34]}$ To move a step further in MSE, individual nanoreactors should be interfaced to form well-defined multifunctional networks. The emergent properties of such networks could be tuned by varying the number and the molecular

\begin{tabular}{|c|c|c|c|c|}
\hline & System & Component & Emergent Property & Interfacing \\
\hline & - & Streptavidin & - & - \\
\hline & Primary System & $\begin{array}{l}\text { a) Transporter } \\
\text { b) Catalyst }\end{array}$ & $\begin{array}{l}\text { a) Cellular Uptake } \\
\text { b) Stereoselectivity }\end{array}$ & Molecular Recognition \\
\hline & Secondary System & a) Fluorophore & a) Cellular Imaging & \\
\hline MSE & & & & \\
\hline
\end{tabular}

Fig. 7. Streptavidin as primary component for non-covalent systems engineering. Compare Fig. 6 for structures and Fig. 1 for definitions. specificity of the interfacing sites. To this end, blends of two primary components, non-functionalized and tris(nitrilotriacetic acid) functionalized poly(butadiene)- $b$ poly(ethylene oxide) polymers, were assembled in aqueous conditions. These primary systems, trisNTA decorated polymersomes 21, exhibited emergent metal ion mediated binding affinity to various proteins/peptides, yielding functional secondary systems 22.[35] These basic studies enable reliable step-by-step engineering of catalytic nanoreactor networks as part of the roots of molecular factories.

With cells or devices as primary components, similar systems analysis of realized examples and systems engineering for future coupled systems can be easily formulated. For instance, the systems analysis made for cell-penetrating red-fluorescent secondary systems $\mathbf{1 1}$ could also be made with cells instead of streptavidin $\mathbf{8}$ as primary component (Figs 6 and 7). ${ }^{[4]}$

Arguably, chemical metabolism presents the most complex primary component that is interfaced by a plethora of pathways resulting in the primary system of a cell, with the emerging property of life. Interfacing chemical catalytic units with this primary system will generate complex secondary systems that will leverage the biosynthetic potential of organisms by introducing new-to-nature functionality, and by generating chemical reactions not yet feasible in biological systems per se. In addition, it should be pointed out that these secondary systems should be generated $d e$ novo, by assembling molecular new-to-nature components therefore allowing for unprecedented functionality not constrained by genome modification of the underlying primary system. A number of interfacing strategies can be envisioned on a molecular level, and a bio-inspired approach for selection and optimization suggested the use of catechols as building blocks. ${ }^{[7]}$ 


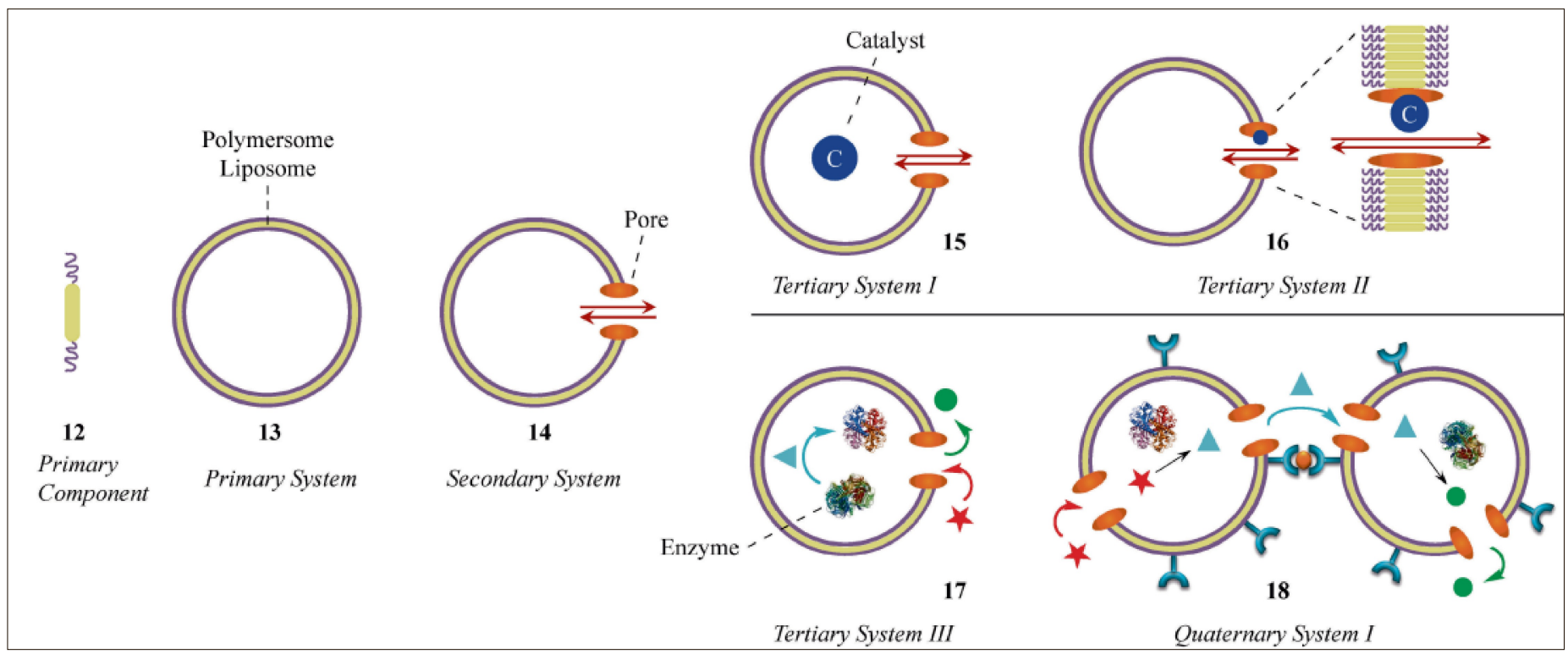

Fig. 8. Non-covalent coupled systems: Amphiphilic polymers 12 or phospholipids as primary components self-assemble into polymersomes or liposomes yielding primary systems 13 . Interfacing of polymersomes with membrane proteins yields secondary systems 14 , in which ions and molecules are able to cross the membrane through the pore. Further interfacing with catalysts, enzymes or catalytic pores affords nanoreactors as tertiary systems 15-17. Interfacing of two nanoreactors is expected to yield quaternary systems $\mathbf{1 8}$. Interfacing tertiary systems $\mathbf{1 7}$ with cells lead to artificial organelles as quaternary systems. Compare Fig. 9 for explicit systems analysis.

Recognizing the potential of siderophorederived catechols for surface functionalization, ${ }^{[36]}$ we developed this platform for a variety of applications, from antimicrobial surfaces to neuritogenic materials. ${ }^{[37]}$ We think that this bio-inspired catecholate platform has tremendous potential for interfacing functional systems and thus introducing new-to-nature functionality in living systems.

Overall, the unifying theme among the analyzed examples for covalent, dynamiccovalent and non-covalent coupled systems is the interfacing of functional components and the emerging properties obtained. The objective of the NCCR MSE is to drive this cumulative interfacing to the extreme and achieve unprecedented levels of sophistication and multifunctionality. Calling for extraordinary creativity, no one really knows where this cumulation of emergent properties beyond the classical systems chemistry will lead to. Ultimately, MSE is expected to provide access to processes that a) are important and b) cannot be realized otherwise, with more conventional

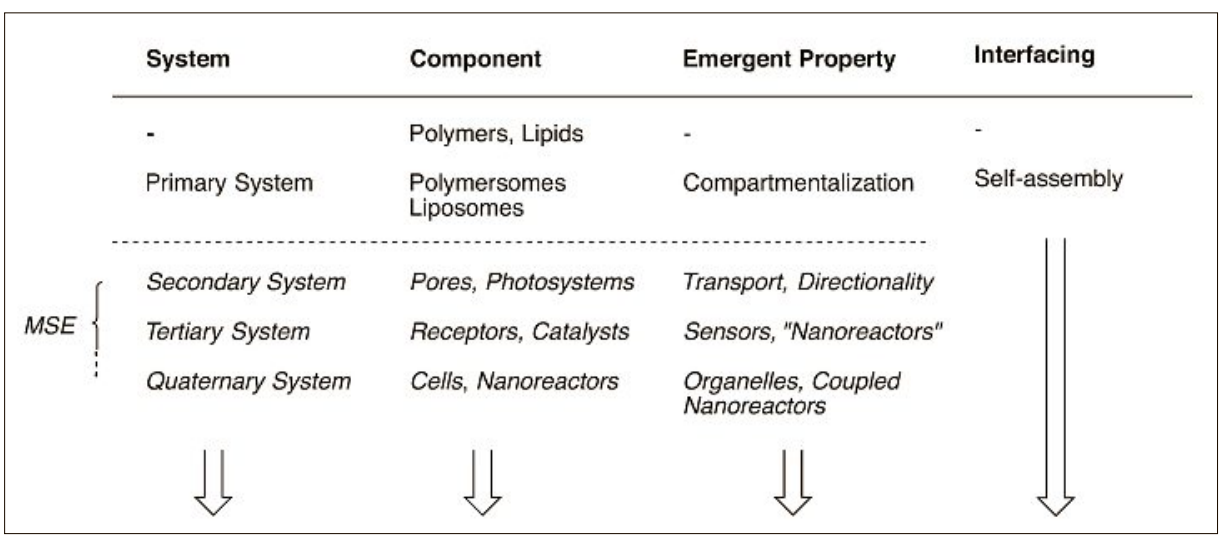

Fig. 9. Polymersomes and liposomes as primary systems for non-covalent systems engineering. Compare Fig. 8 for examples and Fig. 1 for definitions.

approaches. Moreover, lessons learned on the way will help improve on some current limitations such as the ability to synthesize not small molecules but large and complex molecular architectures with high precision, to have more than two orthogonal dynamic covalent bonds available for interfacing, to deliver whatever is needed into cells, and so on, not to speak of all the analytical challenges involved. Interfacing different functional systems from different disciplines with different expertise, molecular systems engineering calls for collaborative work. One of the most important objectives of the NCCR MSE is to help initiate these decisive collaborations.

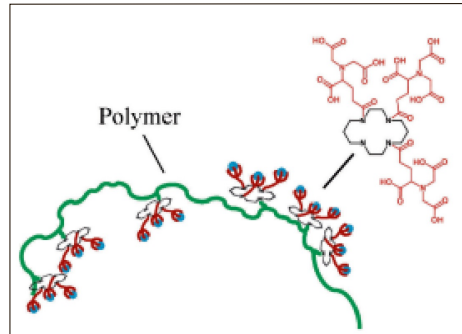

19

Primary System

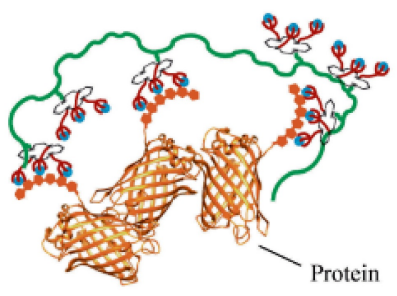

20

Secondary System

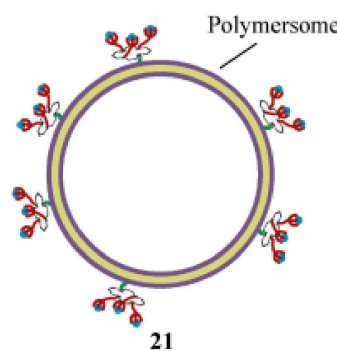

Primary System

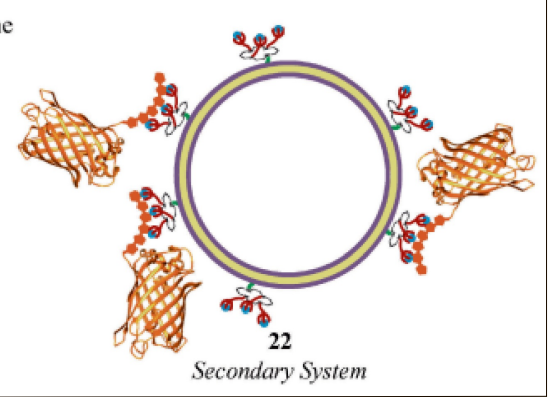

Fig. 10. Non-covalent metal coordinated MSE: Interfacing of functionalized polymers 19 or polymersomes 21 as non-covalent primary systems. Interfacing these primary systems with fluorescent His $_{6}$-tagged proteins $\mathbf{2 0}$ (orange) via metal coordination (blue) yields secondary systems $\mathbf{2 0}, \mathbf{2 2}$ with emergent fluorescent properties. 


\section{Acknowledgements}

We thank all past and present coworkers and collaborators for their contributions to this research, and the National Centre of Competence in Research (NCCR) Molecular Systems Engineering, administered by the Swiss NSF, for financial support. Gratefully acknowledged is additional financial support from the Universities of Geneva (SM), Basel (TW, CP, WM) and Zurich (KG), the ETHZ (SR), and the Swiss NSF.

Received: March 20, 2016

[1] http://www.nccr-mse.ch/en/

[2] Y. Zhao, Y. Cotelle, A.-J. Avestro, N. Sakai, S Matile, J. Am. Chem. Soc. 2015, 137, 11582.

[3] a) B. Baumeister, N. Sakai, S. Matile, Org. Lett. 2001, 3, 4229; b) N. Sakai, N. Sordé, S. Matile, J. Am. Chem. Soc. 2003, 125, 7776.

[4] G. Gasparini, S. Matile, Chem. Commun. 2015, 51,17160

[5] H. Hayashi, A. Sobczuk, A. Bolag, N. Sakai, S. Matile, Chem. Sci. 2014, 5, 4610.

[6] T. R. Ward, Acc. Chem. Res. 2011, 44, 47.

[7] K. Gademann, Acc. Chem. Res. 2015, 48, 731.

[8] T. A. Khan, S. T. Reddy, Acta Biomat. 2014, 10, 1720.

[9] C. G. Palivan, R. Goers, A. Najer, X. Zhang, A. Car, W. Meier, Chem. Soc. Rev. 2016, 45, 377

[10] a) K. Fujisawa, M. Humbert-Droz, R. Letrun, E. Vauthey, T. A. Wesolowski, N. Sakai, S. Matile, J. Am. Chem. Soc. 2015, 13, 11047; b) K. Fujisawa, C. Beuchat, M. Humbert-Droz, A. Wilson, T. A. Wesolowski, J. Mareda, N. Sakai, S. Matile, Angew. Chem. Int. Ed. 2014, 53, 11266.

[11] a) Y. Zhao, Y. Domoto, E. Orentas, C. Beuchat, D. Emery, J. Mareda, N. Sakai, S. Matile, Angew. Chem. Int. Ed. 2013, 52, 9940; b) Y Zhao, C. Beuchat, J. Mareda, Y. Domoto, J. Gajewy, A. Wilson, N. Sakai, S. Matile, J. Am. Chem. Soc. 2014, 136, 2101.

[12] a) Y. Zhao, S. Benz, N. Sakai, S. Matile, Chem. Sci. 2015, 6, 6219; b) Y. Cotelle, S. Benz, A.-J. Avestro, T. R. Ward, N. Sakai, S. Matile, Angew. Chem. Int. Ed. 2016, 55, 4275 .
[13] M. Lista, J. Areephong, N. Sakai, S. Matile, J. Am. Chem. Soc. 2011, 133, 15228.

[14] N. Sakai, S. Matile, J. Am. Chem. Soc. 2011, $133,18542$.

[15] K.-D. Zhang, S. Matile, Angew. Chem. Int. Ed. 2015, $54,8980$.

[16] K.-D. Zhang, N. Sakai, S. Matile, Org. Biomol. Chem. 2015, 13, 8687.

[17] a) N. Sakai, P. Charbonnaz, S. Ward, S. Matile, J. Am. Chem. Soc. 2014, 136, 5575; b) G. Sforazzini, E. Orentas, A. Bolag, N. Sakai, S. Matile, J. Am. Chem. Soc. 2013, 135, 12082.

[18] A. Wilson, G. Gasparini, S. Matile, Chem. Soc. Rev. 2014, 43, 1948.

[19] S. Hagihara, H. Tanaka, S. Matile, J. Am. Chem. Soc. 2008, 130, 5656

[20] T. K. Hyster, L. Knörr, T. R. Ward, T. Rovis, Science 2012, 338, 500

[21] M. Dürrenberger, T. Heinisch, Y. M. Wilson, T. Rossel, E. Nogueira, L. Knörr, A. Mutschler, K. Kersten, M. J. Zimbron, J. Pierron, T. Schirmer, T. R. Ward, Angew. Chem. Int. Ed. 2011, 50, 3026.

[22] a) G. Gasparini, E.-K. Bang, G. Molinard, D. V. Tulumello, S. Ward, S. O. Kelley, A. Roux, N. Sakai, S. Matile, J. Am. Chem. Soc. 2014 136, 6069; b) G. Gasparini, G. Sargsyan, E.K. Bang, N. Sakai, S. Matile, Angew. Chem. Int. Ed. 2015, 54, 7328; c) E.-K. Bang, G. Gasparini, G. Molinard, A. Roux, N. Sakai, S. Matile, J. Am. Chem. Soc. 2013, 135, 2088; d) E.-K. Bang, M. Lista, G. Sforazzini, N. Sakai, S. Matile, Chem. Sci. 2012, 3, 1752.

[23] F. Itel, M. Chami, A. Najer, S. Lörcher, D. Wu, I. A. Dinu, W. Meier, Macromolecules 2014, 47, 7588.

[24] F. Itel, A. Najer, C. G. Palivan, W. Meier, Nano Lett. 2015, 15, 3871.

[25] a) M. Lomora, M. Garni, F. Itel, P. Tanner, M. Spulber, C. G. Palivan, Biomaterials 2015, 53 , 406; b) M. Lomora, I. A. Dinu, F. Itel, S. Rigo, M. Spulber, C. G. Palivan, Macromol. Rapid. Comm. 2015, 36, 1929.

[26] a) S. Bhosale, A. L. Sisson, P. Talukdar, A. Fürstenberg, N. Banerji, E. Vauthey, G. Bollot, J. Mareda, C. Röger, F. Würthner, N. Sakai, S. Matile, Science 2006, 313, 84; b) A. PerezVelasco, V. Gorteau, S. Matile, Angew. Chem. Int. Ed. 2008, 47, 921.

[27] A. Graff, C. Fraysse-Ailhas, C. G. Palivan, M. Grzelakowski, T. Friedrich, C. Vebert, G.
Gescheidt, W. Meier, Macromol. Phys. Chem. 2010, 211, 229 .

[28] a) T. Takeuchi, S. Matile, Chem. Commun. 2013 49, 19; b) P. Talukdar, G. Bollot, J. Mareda, N. Sakai, S. Matile, Chem. Eur. J. 2005, 11, 6525; c) N. Sakai, S. Matile, Chem. Commun. $\mathbf{2 0 0 3}$, 38, 2514; d) N. Sakai, B. Baumeister, S. Matile, ChemBioChem 2000, 1, 123 .

[29] D. Dobrunz, A. Toma, P. Tanner, T. Pfohl, C. G. Palivan, Langmuir 2012, 28, 15889.

[30] T. Einfalt, R. Goers, I. A. Dinu, A. Najer, M. Spulber, O. Onaca-Fischer, C. G. Palivan, Nano Lett. 2015, 15, 7596 .

[31] a) K. Langowska, C. G. Palivan, W. Meier, Chem. Commun. 2013, 49, 128; b) Langowska, J. Kowal, C. G. Palivan, W. Meier, J. Mater Chem. B 2014, 2, 4684.

[32] a) S. Egli, M. G. Nussbaumer, V. Balasubramanian, M. Chami, N. Bruns, C. Palivan, W. Meier, J. Am. Chem. Soc. 2011 133, 4476; b) L. H. Dieu, D. Wu, C. G. Palivan, V. Balasubramanian, J. Huwyler, Eur. J. Pharm. Biopharm. 2014, 88, 316.

[33] P. Tanner, V. Balasubramanian, C. G. Palivan, Nano Lett. 2013, 13, 2875.

[34] a) J. Liu, V. Postupalenko, J. T. Duskey, C. G. Palivan, W. Meier, J. Phys. Chem. B 2015, 119 , 12066; b) J. Liu, M. Spulber, D. Wu, R. M. Talom, C. G. Palivan, W. Meier, J. Am. Chem. Soc. 2014, 136, 12607.

[35] a) R. Nehring, C. G. Palivan, O. Casse, P. Tanner, J. Tüxen, W. Meier, Langmuir 2009, 25, 1122 b) R. Nehring, C. G. Palivan, S. Moreno-Flores, A. Mantion, P. Tanner, J. L. Toca-Herrera, A. Thunemann, W. Meier, Soft Matter 2010, 6 2815 ; c) P. Tanner, M. Ezhevskaya, R. Nehring, S. Van Doorslaer, W. Meier, C. Palivan, J. Phys. Chem. B 2012, 116, 10113 .

[36] a) B. Malisova, S. Tosatti, M. Textor, K. Gademann, S. Zürcher, Langmuir 2010, 26 , 4018; b) S. Zürcher, D. Wäckerlin, Y. Bethuel, B. Malisova, M. Textor, S. Tosatti, K. Gademann, J. Am. Chem. Soc. 2006, 128, 1064

[37] a) P. Burch, F. Schmid, K. Gademann, $A d v$ Healthcare Mater. 2014, 3, 1415; b) J. Gomes, A. Grunau, A. K. Lawrence, L. Eberl, K. Gademann, Chem. Commun. 2013, 49, 155; c) J. Hoecker, R. Liffert, P. Burch, R. Wehlauch, K. Gademann, Org. Biomol. Chem. 2013, 11, 3314; d) J.-Y. Wach, S. Bonazzi, K. Gademann, Angew. Chem. Int. Ed. 2008, 47, 7123. 